\title{
Aaron Antonovsky (1923-1994): \\ The Personal, Ideological, and Intellectual Genesis of Salutogenesis
}

\author{
Avishai Antonovsky and Shifra Sagy
}

"Your candle burned out long before your legend ever did" (Bernie Taupin, Candle in the wind).

\section{Introduction}

In January 1945, while serving in the American army and stationed in New Guinea, Aaron Antonovsky (hereafter Aaron) wrote a long letter to his younger brother, Carl, who was then 13, ongoing adolescence. Aaron, at the age of 21, expressed two things that would later on become a significant part of his academic character. He wrote: "You don't know the meaning of 'iconoclast' - but you know the idea, because Avraham Aveenu [Abraham, one of the fathers in the Bible] was one. What did he do? He looked all about him, questioned everything, rebelled against everything ... and he mercilessly destroyed everything that was false. He broke not only the idols themselves, but the belief he himself had once had in them. He had not yet discovered the great principle of his life, but he had cleared the way for it." Years later, perhaps less dramatically, pathogenesis was "removed" from the agenda to make way for salutogenesis. Toward the end of the letter, Aaron wrote: “... throughout our lives, we must never stop asking questions; but it is most important now." A half a century later, in a tribute to Aaron, Ilona Kickbusch wrote "... there is nothing more practical and efficient than asking the right question .... Aaron Antonovsky consistently

This chapter is a revision and update of work published in Mittelmark, M.B., Sagy, S., Eriksson, M., Bauer, G., Pelikan, J.M., Lindström, B., \& Espnes, G.A. (eds). (2017). The Handbook of Salutogenesis. Springer, Cham. DOI: https://doi.org/10.1007/978-3-319-04600-6

A. Antonovsky $(\square)$

Department of Health and Well-being, Medical Corps, Israel

Defense Forces, Ramat-Gan, Israel

e-mail: Antonovsky.soc@gmail.com

\section{S. Sagy}

Martin Springer Center for Conflict Studies, Ben-Gurion

University of the Negev, Be'er Sheva, Israel had the courage to ask the right question: how is health created?" (1996, p. 5).

Rebelling against the mainstream and searching for the right questions seem to be the two most salient characteristics that bridge between Aaron the scholar and Aaron the man.

In this chapter, we wish to share some insights we have regarding the development of the salutogenic idea, by drawing lines connecting it to the person Aaron was. Having been very close to Aaron for several decades, we feel that a certain degree of familiarity with his personal background would contribute to the understanding of the development of the salutogenic theory. Therefore, we wish to shed some light on Aaron's personal experiences, ideological beliefs, and professional development throughout his life, until the crystallization of the salutogenic idea. Being close to him, and knowing what he would prefer, we shall refer to him by first name throughout this chapter (unless quoting others).

But how does one write about Aaron the scholar, without diving too deeply into the world of salutogenesis, which will be discussed thoroughly throughout this book? How does one write about Aaron the man, without becoming too biographically boring? We shall try to accomplish this task by avoiding strict academic writing; instead, following a brief history of his life, we will highlight a few qualities which, we believe, are characteristic of Aaron's scholarly work and his personal life. In doing so, we will quote friends and colleagues of Aaron's who have agreed to contribute their illustrative memories to this chapter. ${ }^{1}$ These will be embellished with some unknown, perhaps humorous, anecdotes.

\section{Rebellion and the Importance of Questions}

Aaron was born in the United States in 1923, 5 years after the end of World War I and 6 years before the outburst of the Great Depression. His parents and older sister had fled from Russia a few years earlier, arrived in Canada, traveled

\footnotetext{
${ }^{1}$ The names of these people are marked in bold typeface.
} 
to England, and back to Canada before they finally settled down in Brooklyn, New York. As a child, Aaron's social environment consisted of immigrant families, mostly lower-class Jews and Italians. His father owned a small laundry shop where his wife and two older children spent many hours helping out. Somehow, they managed to survive the difficulties of adapting to a new culture in times of a severe economic depression. Later, in the 1930s, Aaron's parents-for whom education was extremely important (having little or no formal education themselves)—sent him to a prestigious high school, and then to college, until he was drafted into the American army during World War II and sent to the Pacific.

As an adolescent, Aaron was deeply involved in the HaShomer HaTza'ir Jewish youth movement, where he first absorbed a socialistic ideology. As his younger brother Carl told us, "Belonging to a Jewish organization was obvious." Selma Rieff, a close friend, who met Aaron as a child in the youth movement, remembers those days, of endless ideological discussions, as most important in shaping Aaron's orientation to life.

This was perhaps the first instance of Aaron the rebel because unlike most movement members, he was against Communism. At the age of 26, after the establishment of the State of Israel in 1948, Aaron came to Israel and was a founding member of a kibbutz, ${ }^{2}$ where his socialist ideology came into practice.

Upon returning to the United States in the early 1950s, Aaron completed his doctorate in sociology at Yale University. By that time, he had been involved in research and writing about social class, discrimination, inequality, immigration, and ethnic minorities. During this period, we believe, the seeds were planted for what would a quarter of a century later evolve into being the salutogenic model. For Aaron, the two decades between 1955 and 1975 were years of transition: personally, he had married, spent a year in Iran and then came back to Israel (this time to the city of Jerusalem), had a child born, and ended up in the city of Beer Sheva, helping to set up a new medical school. Professionally, Aaron moved back and forth between the sociological studies on immigration, culture, and social class, and the focus on sociology of health. During this period, he was coauthor or coeditor of four books, which are possibly not familiar today to health promotion scholars, but we see them as tied to the salutogenic revolution: Poverty and health (1969), Hopes and fears of Israelis

\footnotetext{
${ }^{2}$ A kibbutz (in Hebrew: collection; plural: kibbutzim) is an Israeli unique kind of collective settlement. A person living in a kibbutz is a kibbutznik. There are a few hundred kibbutzim; the first established in 1909. Traditionally based on agriculture, they began as utopian socialist communities, carrying the slogan "From each according to his ability, to each according to his need." Today, many kibbutzim have been privatized, and industry has replaced much of the agriculture.
}

(1972), From the golden to the promised land (1979), and A time to reap (1981).

People suffering discrimination, or poverty, or the struggle to adjust to a new country as immigrants (or founding a kibbutz on bare land in the summer heat or the winter cold), are quite obviously prone to physical or mental sickness. Still, many such people maintain good health and well-being. The question that began to arise in Aaron's mind was not why some of these people feel miserable, but rather how some of them manage quite well. This question became more salient following a study of women Holocaust survivors, many of whom were found to be well adapted, despite the excruciating experience in concentration camps and poor life conditions after immigration to Israel.

The answer, which Aaron has termed the sense of coherence, was to follow. But it was the salutogenic question-not why does one become sick but how does one move toward the health pole on the ease-dis-ease continuum - that constituted the major philosophical change in thought, from the traditional pathogenic orientation to the salutogenic view of the mystery of health.

The emphasis on asking the right question, as a key to relevant answers, is, we believe, crucial to the advancement not only of the study of health and well-being but also of all scientific endeavors. Aaron's mantra "Ask the right question!" has been following one of us (AA), first as a teenager, later as a young student, and to these days as a researcher in the social sciences; it is useful in the academia, but no less in solving "simple" daily problems, be it why the TV remote control does not work or where to go on the next vacation.

Asking questions, in itself, is a kind of rebellion. It signifies resistance to blind acceptance. But Aaron wanted more. Aaron put into deeds the words attributed to Mark Twain: "Whenever you find yourself on the side of the majority, it's time to pause and reflect."

From a personal-developmental perspective, we see the roots of Aaron's salutogenic theory in his concrete childhood and adolescence experiences, from which he derived the tendency to question the world and rebel against what he believed was wrong. In a recent conversation, his younger brother Carl described him as "very idealistic, striving for a better world, intellectually curious, full of compassion, and having a strong feeling of how things should be done."

Aaron's parents, optimistically tackling the daily hurdles in the time of the Great Depression, served for him as living examples of viewing life as comprehensible, manageable, and meaningful. It is, therefore, clear why he dedicated his book Unraveling the mystery of health (1987b) "To my parents ... from whom I learned about the sense of coherence." A good illustration of the strong bond between Aaron and his 


\section{Antonovsky aharon Esige Inglish 30 I5 \\ May I3 I940}

Remembrantes of warmth and life.

The dishes were stili on the table. The bright kitchen lights provided a contrast to the derkness all about us. The hissing sound of the radi ator reminded us of the fierce frost raging outside. I, a little boy with girlis hair, sat on the chair satisfied to the fullest extent. Eyes and ears wide open, I listened. Ny mother, the center of my worja, sat next to me, the book open on her lag, reading to her little son. This scene is engraved upon my memory. Truo, age has put a halo arounc it, romanticized it, but it stands out clearly in my mind as Ine of the most beautiful times of my childhood. For several months each evening I would be transported to another world, a world where people lived clean, wonderful $15 \mathrm{ves}$, and fought against filth and degracition and oppression. Night after night the two of us would sit down after supper and my mother would read.It was "mother "by Gorki that so enchanted the two of us.My mother would read several lines in the russian and transmit the beaty and idea in them to mein jewish. In spite of the fact that I was far too young to appreciate the entire meanjing of the book it was one of the most important things that ever happened to mo, Why? First,it acted as a stlmulant in my choice of reading. The boauty and hardness nf reallty-of the book provided a basis for shaping my way of thin̄king and of life of a city child......dis cribable only by the smile on the face of a sieeping infant or the joy one experiences when one lives for an hoyr a day, a jearwith the vibrant smell of the freshness of trees and green grass penetrating one's nostrilis- I felt the contentment and warmth of one physically and mental $1 y$ living a pure, healthy life.

And now when my mother sees me she thinks of the seeds she impregnate

within me- the seeds of revolt. A i rebellibas, son

faces her. But she does npt realize that this is the only way-that It is an immutable law for the son to revolt, to demand to live his own way of life.I am mu mother's son. She has taught me thus.Could she but grasp the spark that burns within me, that she hersele has planted I wovld be happy. It has been such a long time that I jave written here.Probably the most important part of my life till now has passed. during this time.why have I not writing anything. For whom I am I writing? who shall see this?

Fig. 4.1 High school essay by Aaron Antonovsky (yellow markings added by the authors)

mother, his early idealistic thoughts of social justice and health, and his tendency toward rebellion is found in an excerpt from an English essay he wrote in high school at age 16. The original, in Aaron's handwriting, was typewritten by him several years later (see Fig. 4.1). His essay, by the way, earned him a B+ mark.

\section{Warmth and Informality Versus Strictness and Academic Demands}

Several colleagues and friends have pointed out two characteristics of Aaron that we know very well, and - we believehave enabled him not only to make his way to the hearts of other people but also to be a good researcher and health edu- 
cator: informality, on the one hand, and uncompromising academic demands, on the other.

In a Western professional world where it is a custom to go to work with shoes, a jacket, and a tie, Aaron was known for his appearance with sandals, a short-sleeved shirt, and of course no tie. This habit may have its origin in the kibbutz life, and it was probably very convenient to wear such an outfit in Beer Sheva (where Aaron lived for 18 years while at Ben Gurion University of the Negev). ${ }^{3}$ We assume that on very formal occasions abroad (i.e., outside Israel) he would wear a tie, but in our memories (at least for AA), the only time Aaron wore a suit and a bow-tie was for the ceremony in 1993, in which he received an honorary doctorate at the Nordic School of Public Health in Göteborg, Sweden.

An illustration of Aaron's openness, talkativeness, and informality is found in an article by Suzanne C. Ouellette (Kobasa). In 1998, a special issue of Megamot ("Trends"the leading Israeli behavioral sciences journal) was devoted to "Salutogenesis and wellness: Origins of health and wellbeing." Ouellette, who developed the concept of hardiness at about the same time that the idea of the sense of coherence was born (e.g., Kobasa, 1979), wrote an article for the special issue, titled "Remembering Aaron Antonovsky: A conversation cherished and one missed." Here are a few excerpts of that article (Ouellette, 1998), back-translated from Hebrew (unfortunately, we were unable to find the original English manuscript, which was translated into Hebrew for the special issue):

I had only one opportunity to meet Aaron Antonovsky and enjoy a lively, open, and informal conversation about research questions that had interested us. It took place at his parents' apartment in Brooklyn, New York. It was in summer 1982, only a few years after each one of us published, without being introduced to each other, what we had thought were new and unique calls for research about the things that keep people healthy under stress.

In the phone conversation we had before that meeting, Aaron explained that he was visiting his parents and told me a bit about them and his relationship with them. His parents lived during the time of the Holocaust and were now in their old age. His visit was to make sure they are alright. It was also an opportunity for him to gain strength from two people who had been, and still were, key figures for him; an example of how people live, in Aaron's words, a salutogenic life.

At the meeting itself I got the impression that Aaron's parents were full of vitality despite their age (his father was over 90 and his mother was approaching 90). They did what was needed to make sure their son's stay in New York would be comfortable and that our meeting would be pleasant for me as well. Aaron was dressed informally: an army-like khaki shirt. I have seen this kind of shirt, but usually in films in a desert area, not in the streets of Brooklyn or Chicago. I wore a suit, but his outfit was more appropriate for the summer heat that day. I looked more or less like I thought that a young lecturer should look like at a meeting with a senior scholar. The clothes remained the only representations of our difference in status. The conversation

${ }^{3}$ Beer Sheva is called the "capital of the Negev." The Negev is a dry, desert-like region in the southern part of Israel. The temperatures range from about $10^{\circ}$ (centigrade) in the winter to $35-40^{\circ}$ in the summer. itself was a free exchange of ideas between two people who had committed themselves to certain questions regarding human behavior, to the search for better-developed theories and for better means to examine such theories.

Much of Aaron's work consisted of simultaneously presenting his own work and the work of others. He developed his ideas by putting them side by side with others' similar ideas. He has given us a lesson on how to work; his intention was not to show that his approach was better; instead, he demonstrated how confrontations between the theoretical and practical ideas of different researchers give rise to new questions, which may bring us closer to a better understanding of human behavior. He showed us that a sense of coherence can be found through the loneliness of writing.

In the same spirit, Rudolf Moos of Stanford University has recently written to us about Aaron:

He loved to engage in discourse with me and several of my colleagues and was always ready and eager to review his ideas and to learn about our comments and criticisms. We had quite a few long conversations about his ideas, which were incisive, original, and rather revolutionary for the time.

Our own work focused heavily on the positive (and negative) influences of the social context on health and behavior and on the specific ways in which individuals could confront and manage stressful life events and life crises.

Regarding the way Aaron related to others' criticisms, Shifra Sagy (second author) remembers his openness to critical opinions of other researchers, let them be senior or junior. "He may have not been perceived as such in the academia," says Shifra, "but I knew this characteristic of his very well." She elaborates:

He always encouraged me to express my opinion and even to argue with him. He liked to tell the story of how I became research coordinator for his big study on sense of coherence and retirees' adjustment. During my first job interview with him, I said he is very wrong, including only retirees in the study, and that to understand their adjustment to retirement he should also have a sample of the retirees' spouses.

I went home and told my husband there is no chance that I got the job. Apparently, I was wrong; and the rest is history.

Deo Strümpfer, a friend and colleague from South Africa, added:

He was the most supportive colleague and "teacher" a person can ever hope to have. His comments on pre-publication papers were incisive, yet always kind and warm; an amazing aspect was how quickly he responded. He connected persons with similar interests with one another.

Aaron's informality has apparently struck the memories of several other colleagues and students. Moshe Prywes, the first Dean of the Beer Sheva medical school (died in 1998), said: "I first met Aaron when he was a fellow at the Guttmann Institute of Applied Social Research at the Hebrew University of Jerusalem. I couldn't help but notice the man who was wearing shorts and sandals." (Prywes, 1996, p. ii). Asher Shiber, a medical student and later a colleague, lately recalled that once every week or two, Aaron (and his wife, 
Helen) would invite two or three students to their house for dinner. Ayala Yeheskel, a social worker in Beer Sheva in the mid-1980s, told us:

A while before a meeting with Antonovsky in January 1985, I lost my son, Eldad. At the time I was employed as a social worker in the Department of Psychiatry and in the Department of Family Medicine at the Soroka Medical Center in Beer Sheva, and spent much time teaching about the biopsychosocial approach. Besides that, I was exploring possible topics for my doctoral dissertation at the Hebrew University of Jerusalem, in the context of life stories of Holocaust survivors. About a month after my personal tragedy, emotionally uneasy, I turned to Antonovsky for counseling. With utmost patience and tenderness, he listened, and at the end of the meeting he asked me a question I will never forget: "Ayala, you are now in the midst of your own private holocaust; how will you engage in a subject you are so personally close to? In any case, I will help you and wish you good luck." I felt I had received approval, from an admired and beloved person, of my ability-in spite of my personal circumstances - to carry on with the tasks I had planned for myself.

Aaron's informality and warmth were expressed not only toward his colleagues and students. Several times, while on visits abroad, Aaron was interviewed by local newspapers. One would expect that a serious professor, a well-known scholar in his field, would present himself in formal dress. However, some photos show this was not the case: he was photographed riding a bicycle or wearing short pants because that is what made him comfortable (unfortunately, the authors' attempts to contact the newspapers and obtain permission to use the 30- to 40-year-old photos were unsuccessful).

\section{The Establishment of the Medical School and the "Beer Sheva Spirit"}

Although not directly related to salutogenesis or to Aaron's personal characteristics, it seems that a short background on the establishment of the medical school in Beer Sheva is needed in order to put several of the quotes and stories hereafter in context. Shimon Glick, professor of internal medicine and former Dean of the Faculty of Health Sciences at Ben Gurion University of the Negev, who worked with Aaron from the first days of the medical school in the early 1970s, described the formation of the "Beer Sheva spirit" and Aaron's contribution to it:

When Professor Moshe Prywes of Hebrew University and Dr. Haim Doron of Kupat Holim ${ }^{4}$ launched the new medical school at Ben Gurion University of the Negev it was not to produce another medical school, but to create an educational institution of another type entirely. This was to be a school which would

\footnotetext{
${ }^{4}$ Kupat Holim, literally meaning "sicks' fund," is the Israeli health plan
} and medical insurance institution. train humanistic physicians with an orientation to the needs not only of their specific patients but to the needs of the community in which the school is located. These physicians would be sensitive to the psychosocial and cultural aspects of medicine. Wonderful sounding words, but really neither of the two founders of the school, nor hardly any of the existing staff or of the staff recruited to begin to teach at the school had any real concept of how to accomplish this great and important mission. Prywes recruited Aaron to be the spirit and guiding light of the project. Aaron was a scholar in sociology of health, most of it theoretical, as sociology usually is; now here was an amazing challenge and opportunity to apply sociology to the creation of an institution which would train a new kind of physician to serve his/her community in the ideal manner, sensitive to the cultural and psychological needs of the patients and their community. Aaron was not just one of several department heads recruited to join the new medical school, but was perhaps the key individual who contributed to expressing and articulating clearly the school's goals and direction. He was among the handful of individuals who laid the framework for the school. Among the revolutionary concepts were exposure of students in their first school year to patients not just in the hospital, but in their community settings, teaching them how to speak to the patients, how to understand the influence of their surroundings, economic and social conditions on their illness and the like. But first you had to pick the right kind of students who would be open to this kind of educational orientation. So, one had to change the selection process which heretofore depended only on academic achievements.

All of these steps Aaron designed and taught us, step by step. Speaking for me personally, who arrived as professor of internal medicine in 1974 when the school opened, these ideas were new. I had never heretofore read an article in medical sociology, had never even heard of Antonovsky, but quickly became in some way a devoted follower of his. His ideas and concepts resonated with me and we shared fully the goals. He taught us how to interview patients, how to teach students to do so. He also created the admission process to the medical school, helped select the members of the admission committee, trained them and set into motion a unique process that has continued successfully for several decades. His leadership, absolute integrity and idealism permeated the process and made the admission committee a most prestigious and respected unit in the school, trusted by all.

In reality, most physicians and basic scientists at the institution did not really fully comprehend and buy into his philosophy, because their focus and training had been in the traditional biomedical model. But Aaron influenced enough of the key people and had the full support and backing of the medical school leadership. I believe that the so called "Beer Sheva spirit," which characterizes the school and its graduates to this day, is the spirit instilled by Aaron. And in the spirit of salutogenesis that is what keeps the institution on the "right" track often in the face of adversity and administrative and bureaucratic problems.

On a more personal level, Shimon Glick mentioned that during almost 20 years of working together with Aaron at the medical school, himself being religious and Aaron growing up in HaShomer Hatza'ir (encompassing great ideological differences and conflicting outlooks), they have always respected one another and had much in common.

Milka Sampson is secretary of the Department of Sociology of Health at Ben-Gurion University, of which Aaron was chairperson. She worked with Aaron from the time she was appointed, in 1984, until he formally retired in 
1993. She described Aaron as "an honest and fair man, from whom I learned so much." She was a beginner secretary in her early 20s and remembers that "Professor Antonovsky" insisted she call him "Aaron." Before Milka, there was a secretary who would always address him as "professor." Ofra Anson, who worked with Aaron in the Department of Sociology of Health for almost 20 years, told us in a recent interview that Aaron once said to her in despair, relating to the secretary: "For Heaven's sake, we work together! Why doesn't she stop calling me 'the professor'?!"

Shifra Sagy (second author), who was Aaron's doctoral student and later a colleague in the department, mentioned the "Friday cakes": every Friday, it was someone else's turn to bring a cake to the staff meeting. Aaron had insisted that each one must prepare a cake by him/herself (one time, on his turn, he wanted to bake a fruit cake, but the only fruit he had at home was a grapefruit; so he baked a grapefruit cake ...). In these matters, everyone belonged to the same social status. For example, they would all take turns washing dishes.

The Friday gatherings were devoted not only to professional matters. Actually, this was also an opportunity to discuss a good book someone had read, or to celebrate someone's birthday, or to argue about politics. However, even though Aaron's belief system has probably influenced several of his career choices, he meticulously separated ideology from scientific objectivity. Zeev Ben-Sira, a medical sociologist from the Hebrew University of Jerusalem who passed away about a year after Aaron, addressed this issue in an obituary written a short while after Aaron's death (1995, unpublished):

Aaron was an idealist, believing in the future of a better and just world. He vehemently contended against social injustice, discrimination, and intolerance. However he unpromisingly separated between his beliefs and his scholarly work. He strongly resisted any intrusion of ideologies into scientific objectivity.

Doubtlessly, his beliefs in a better world influenced the choice of the field of his scholarly work, yet did not contaminate the objective, scrupulous and unbiased approach to his research.

Understandably, then, his initial steps in his scientific career and research were devoted to the study of social discrimination, inequality, intergroup and ethnic relations, and of the absorption of immigrants.

Aaron's personal affection was combined with the great importance he ascribed to community medicine. Aya Biderman, a family doctor, recollects her meeting with Aaron:

In 1980 I arrived for internship at the Soroka Medical Center in Beer Sheva, after studying medicine in Jerusalem. During that year I came to know Dr. Aaron Antonovsky, or "Aaron" as he insisted that we call him.

In 1981 I began to specialize in family medicine. The Department of Family Medicine was next door to the Department of the Sociology of Health, of which Aaron was chairperson.
Aaron had special feelings toward our profession. He said family medicine was one of the "islands" in which the biopsychosocial model should be applied.

As a young doctor, I conducted a study on the reasons why some patients do not attend their family doctor. I hoped to have it published and thought the data may interest Aaron. I met with him to ask for his help, and he agreed. Thanks to him I had my first publication in the medical literature. Aaron's willingness to help a young doctor, who had no experience in research or writing, was very significant and gave me the push and the enthusiasm toward research and academic practice.

Aaron also agreed to teach a biopsychosocial seminar in our department. It was a great learning experience which we (the young doctors) carried with us for years.

The duality of Aaron the man and Aaron the scholar was also expressed in daily work. Alongside with the warm atmosphere and informal relationships in the department, Aaron was strict about work. The department was quite small (6-7 people), and it was important for Aaron that each one would know what others were working on, as a means of mutual fertilization. He demanded from himself what he asked of others, even when it came to things normally done by junior research assistants, such as counting questionnaires. Shifra recalls that when she was beginning her doctorate, Aaron insisted that she write in English. She then gave him her handwritten draft of part of her work. The next day, Aaron gave it back to her, typewritten and corrected.

Indeed, Aaron gave his students lots of hard work. For Israeli students, most of whom have part-time jobs beside their academic studies, spending hours and hours in the library was not a trivial matter. Asher Shiber remembers his basic studies in medical school with Aaron: "The first thing he did was to send me to the library to read and read and read .... As an enthusiastic medical student, I wanted to do medicine, not read about medical research." As the time passed, though, students realized that hard work is productive, and they learned to appreciate Aaron's strictness. Asher sums this point: "With all my appreciation toward Aaron as a professional, the first thing that comes to my mind when I think of him is how much I loved him as a person."

Reading and reading and reading was not only a home work task which Aaron had given his students. Being a bookworm himself, Aaron believed in broadening one's education. Joel Bernstein, a neighbor, a friend, and a colleague from the life sciences, wrote to us:

Our professional backgrounds might not have led to any aca-
demic interaction was it not for the connection with Judy. ${ }^{5}$
However, from the beginning there were social gatherings and I
found myself in the company of a true intellectual. I do not think
a visit to the Antonovsky home passed without me reviewing the
books lying on the table or in the shelves. The collection was

${ }^{5}$ Judy Bernstein was Aaron's research and teaching assistant and later became a faculty member in the Beer Sheva medical school, where she worked until her premature death in 2001. 
truly eclectic, with a scattering of Yiddish literature (in the original), philosophy, political science (much from the liberal academics of the 1950s and 1960s), and of course sociology and psychology. The Antonovsky abode was no more than 150 meters from ours. They moved in about a year after we did, and like everyone had to install an irrigation system-for which, with only the experience of having done my house, I became the consultant, and occasionally technical assistant. ${ }^{6}$

With Joel's help, Aaron spent several hours working in the garden. The first author of this chapter, having spent much time with Aaron in the garden, thinks it is possible that the seeds Aaron planted in the desert soil around the new house in 1973 were, to some extent, seeds of the salutogenic idea; more than once he would look at a few plants, some dying and some still alive, take a closer look at the green ones, and mumble "I wonder how they survive."

We believe that the importance Aaron saw in informal relationships and in expanding one's knowledge is tied to two unique qualities of the new medical school he had helped to establish, which we touched upon above, quoting Shimon Glick. First, the selection process: unlike at other universities, the main criterion for accepting candidates to medical school was not matriculation grades or psychometric scores, but rather results of two stages of semi-structured interviews. Taking into account criticism on an interview as a selection instrument, it seems that in Beer Sheva they have managed to overcome its disadvantages. As Aaron wrote, "In our case, there has come into being a widespread belief among faculty and students: more humane and responsible, less individualistic and competitive, more compassionate and concerned" (Antonovsky, 1987a).

This quote brings back a story one of us (AA) has heard once from Dina Ben-Yehuda, who was one of Beer Sheva's first graduates. Today she is chair of the Department of Hematology at Hadassah Medical Center in Jerusalem and Dean of the Faculty of Medicine at the Hebrew University. The anecdote occurred when Dina was already a senior doctor at Hadassah (forgive us if there are minor inaccuracies). One evening, a senior citizen in his 80 s was brought by an ambulance to the emergency room (ER), after having experienced dizziness and weakness. The doctor in charge of the ER that evening, a senior resident, had the patient go through blood tests, a neurological test, and an ECG. After reviewing the results, with no significant findings, the resident doctor ordered the nurse to discharge the guy and send him home. A young intern, who was with the resident, then said: "if I may, I suggest we keep him here for the night." The resident's response was "he's fine, nothing's wrong with him, and we need the bed." The intern replied: "Indeed, he seems to be okay; but he's a widower, no one is waiting for him at home. He would probably be happy to be around people, to have someone make him a cup of tea. I'm sure we can find a bed

\footnotetext{
${ }^{6}$ We mourn the sudden death of Joel Bernstein which occurred in 2019
}

for him. Why don't we let him spend the night here and send him home tomorrow morning?"

Dina, who was off duty, happened to be in the ER at that time and overheard the conversation. She later approached the intern and said "You studied in Beer Sheva, right?" No doubt, she knew what she was saying...

The second unique quality of the Beer Sheva medical school was the very early stage at which students faced the real world of treating patients. During their first year, students visited community clinics in development towns in the Beer Sheva region, where they met with the poor, the unemployed, and the immigrants who had lost faith in the government's promises for good life. In addition, each student was hospitalized for a few days, without revealing to the medical staff the fact that they were not real patients. They learned that beside anatomy, physiology, and chemistry, it is of utmost importance to learn about doctor-patient relationships.

Ascher Segall, another neighbor, friend, and colleague, and one of the founders of the Beer Sheva medical school, related to the link between Aaron the medical sociologist and Aaron the person:

\begin{abstract}
One of his most striking characteristics was the ability to maintain complete objectivity as a scholar in parallel with a consistent commitment to the values in which he deeply believed. His development of the theory and practice of salutogenesis attests to his rigor and creativity in research while his focus on the humanistic dimensions of medical education reflected his world view as a human being .... His impact as a teacher at the Ben Gurion School of Medicine went far beyond his formal teaching.
\end{abstract}

The impact Ascher Segall referred to is also reflected in the words of Aaron's students. For example, in a tribute by Moshe Prywes in a special issue of the Israel Journal of Medical Sciences in memory of Aaron, he cited Professor Dina Ben-Yehuda (whom we mentioned earlier), who was a former student of Aaron. Dina was a member of the first class of the Ben Gurion medical school, and 20 years later was Aaron's personal doctor at the Sharet Institute of Oncology in Jerusalem, where he was admitted after being diagnosed with leukemia. Prywes had asked her about Aaron, and she replied: "For Ben Gurion graduates, Professor Antonovsky was not just a name. He was a concept. A concept that contains within it much discussion and debate, all pertaining to the doctor-patient relationship ... I took care of Aaron when he was sick and was with him until he died. During that time, he was in full control of all decisions concerning himself. When his condition deteriorated, he called me into his room and asked me to discontinue all treatment, and he took leave of his family and friends. I feel that I have lost the best of my teachers." (Prywes, 1996, p. ii).

The influence Aaron had on students was reciprocal, and so was the respect students and Aaron felt toward each other. 
Aaron's socialist ideology, and his strong belief in all people being equal, may have played a role in the way he prepared the draft for his first book, Health, stress, and coping (Antonovsky, 1979), as told by Leonard Syme, a colleague from the University of California at Berkeley:

Aaron wrote me in the spring of 1977 to ask if he could spend a sabbatical year at Berkeley. ${ }^{7}$ I said "yes!" immediately of course. When he arrived on campus in the fall of that year, I was able to find him a remarkable office. The office was in the basement of Stephens Hall at the end of a hallway that overlooked Strawberry Creek. It was basically isolated from the rest of the building and looked out over beautiful trees and a babbling little brook.

Then we talked. Aaron said he had this idea about writing a book on something called "salutogenesis." He explained what this word meant and I was captivated. To have one of the world's great scholars come to Berkeley to explore a truly exciting and original idea was one of the great moments in my life. I asked how I could help. He said he would love to give a seminar that fall in which he could explore his ideas. It took two days to recruit an excited class of Social Epidemiology graduate students for the seminar.

What happened next was one of the most amazing things I had ever seen. Aaron welcomed them to the seminar, explained how it would work, and assigned them to critically review a draft chapter that he had written after arriving at Berkeley. The next week, students discussed their assignment and, as they were leaving the room, they were asked to review another new chapter that Aaron had just written during the previous 7 days. This went on for 15 weeks. After the semester ended, Aaron had finished a complete draft of his book and was ready to send it off to a publisher. And the book, was, of course a classic.

What a mind he had! I have thought about this remarkable Antonovsky phenomenon many years since it happened.

In 1983, Aaron returned to Berkeley for another sabbatical, again in an office overlooking the creek. Guy Bäckman, from the Åbo Akademi University in Finland, who met Aaron in Berkeley, wrote to us about their acquaintance:

Unraveling the enigma or mystery of health was at that time a big question and theme among the researchers in Berkeley. Questions of frequent occurrence were "Why are only some of us sick although all of us are, at least in some way, exposed to risks?" and "How do we manage to stay healthy?" I had many fruitful discussions on those themes with Aaron in his office on the Berkeley campus, where, from the window, we could see lots of greenery and running water, which certainly stimulated talk about what it might be that keeps people in good condition and health in changing and sometimes risky and chaotic circumstances.

\section{A Closure and New Horizons}

Haim Gunner, an old friend from the days of the youth movement and today a professor of environmental sciences, beautifully summarized the inseparable arenas that made up Aaron's

${ }^{7}$ In 1977, Leonard Syme was chairman of the Department of Biomedical and Environmental Health Sciences in the School of Public Health at the University of California, Berkeley. life - the quest for a just world of social equality, and the academic journey toward unraveling the mystery of health:

The engaged and enthusiastic academic of his later years slips into the image of the devoted kibbutznik and the fields where we shared tractor and plough. And in the evenings, on a crowded balcony with the hills of Galilee facing us, dissected the future with the complete confidence of youth.

Consciously or otherwise, Aaron's life was the model for the salutogenic principle. Two projects dominated his life: initially, the kibbutz and the model society to be derived from it, and always the ongoing fulfillment of the Zionist ideal. And then the building of the medical faculty at Ben Gurion University around the new concept of the family as the arbiter of the individual's health. For the kibbutz, comprehensibility was derived from the perhaps naive, but nonetheless coherent view that Marxism provided. And not only was the project which promised equality and security to be a local event but one which would eventually pervade the entire social structure. Marxism with its dicta and comprehensive weltanschauung made it eminently predictable. Our belief in our skills and the support of the community made it eminently manageable, and our passionate belief, buttressed by juvenile psychoanalytic insights, that it gave meaning to our lives make the kibbutz and its realization the perfect model for the principles of salutogenesis: comprehensibility; manageability and meaningfulness.

We wish we could devote a few paragraphs to the words Aaron's beloved wife, Helen, would have to say for this book. Unfortunately, Helen passed away in 2007. Along the 36 years of marriage to Aaron, she was his greatest supporter, admirer, and critic. There was probably not even one article, lecture, or book of Aaron's that went to press before Helen had read and approved the manuscript. A research psychologist and scholar in her own right, Helen was an inseparable part of the scholar and the man Aaron was.

Shifra Sagy (second author) has been engaged in salutogenic research throughout her academic career, specializing in social-psychological and collective aspects of sense of coherence. She introduced the salutogenic paradigm into the Department of Education, where she headed the educational psychology program for several years. After her retirement, she is still heading the research center of conflict studies at Ben Gurion University of the Negev, under the philosophical agenda of salutogenesis. Avishai (first author) is a social psychologist and grew up in a "salutogenic" household, but until a few years ago salutogenesis has not been a central part of his academic work. However, currently Avishai is leading the implementation of salutogenic thought, as well as the conduction of research, in the Department of Health and Well-being of the Israeli Medical Corps. This promising line of work is described in more detail elsewhere in this book. Aaron would probably be surprised, and hopefully happy, to learn about this new path salutogenesis is marching on. As it appears, salutogenesis has gone way beyond the scope of medical sciences and health, and has become an interdisciplinary area of research and practice.

Aaron passed away in 1994, but his salutogenic vision continues to stimulate theory, research, and policy-making 
worldwide. We hope students and professionals around the world will profit from this comprehensive handbook on salutogenesis, and perhaps some of them will continue to develop salutogenic research and carry it on to new horizons. After all, salutogenesis is not limited to physical or mental health; it is a philosophy of human existence.

\section{References}

Antonovsky, A. (1979). Health, stress, and coping. San Francisco: Jossey-Bass.

Antonovsky, A. (1987a). Medical student selection at the Ben Gurion University of the Negev. Israel Journal of Medical Sciences, 23, 969-975.
Antonovsky, A. (1987b). Unraveling the mystery of health. San Francisco: Jossey-Bass.

Kickbusch, I. (1996). Tribute to Aaron Antonovsky- 'what creates health'. Health Promotion International, 11, 5-6.

Kobasa, S. C. (1979). Stressful life events, personality, and health: An inquiry into hardiness. Journal of Personality and Social Psychology, 37, 1-11.

Ouellette (Kobasa), S. C. (1998). Remembering Aaron Antonovsky: A conversation cherished and one missed. Megamot, 39, 19-30. (Hebrew).

Prywes, M. (1996). A tribute. Israel Journal of Medical Sciences, 32, i-ii.

Open Access This chapter is licensed under the terms of the Creative Commons Attribution 4.0 International License (http://creativecommons. org/licenses/by/4.0/), which permits use, sharing, adaptation, distribution and reproduction in any medium or format, as long as you give appropriate credit to the original author(s) and the source, provide a link to the Creative Commons license and indicate if changes were made.

The images or other third party material in this chapter are included in the chapter's Creative Commons license, unless indicated otherwise in a credit line to the material. If material is not included in the chapter's Creative Commons license and your intended use is not permitted by statutory regulation or exceeds the permitted use, you will need to obtain permission directly from the copyright holder. 